\title{
TITLE:
}

\section{$<$ News> A Chimpanzee Attacks and Kills a Security Guard in Kigoma}

$\operatorname{AUTHOR}(S)$ :

Kayumboq, Hosea Y.

\section{CITATION:}

Kayumboq, Hosea Y.. <News> A Chimpanzee Attacks and Kills a Security Guard in Kigoma. Pan Africa News 2002, 9(1): 11-12

ISSUE DATE:

2002-06

URL:

http://hdl.handle.net/2433/143403

RIGHT:

Copyright (c) Pan Africa News. 
$<$ NEWS $>$

A Chimpanzee Attacks and Kills
a Security Guard in Kigoma

\author{
Hosea Y. Kayumbo \\ Department of Zoology and Marine Biology, \\ University of Dar es Salaam \\ and Co-Chairman of the Mahale Wildlife \\ Conservation Society \\ P.O. Box 35064, Dar es Salaam
}

A sad story in today's Dar es Sal aam newspapers: a correspondent in Kigoma sadly reports that "a chimpanzee ambushed and killed a resident of Mtwanga Street in Kigoma town, Adriano Msafiri aged 60". The Kigoma Regional Police Commander, Boniface Mgongolwa, confirmed that the chimpanzee had managed to escape from "Kitwe Game Reserve." The poor animal, apparently, appears to have gone all the way 
from this Kitwe Game Reserve to Zungu Beach in Kigoma, where it attacked the unfortunate deceased, Ndugu Adriano Msafiri who was a security guard at the beach. The chimpanzee is alleged by the Regional Police Commander to have gorged the eyes of the late Ndugu Msafiri. Eye witnesses have confirmed that the late Msafiri was attacked and seriously injured by a chimpanzee before being rescued and being rushed to the local District Hospital in Kigoma Township where he later died.

Apparently this appears to be not an isolated incident. Last year, 2001, a game ranger of Kitwe Game Reserve was attacked and seriously injured by a chimpanzee, according to the PST reporter in Kigoma. This unnamed last year's victim was lucky in a way, because after prolonged intensive medical treatment he managed to recover. The PST reporter explains further that Kitwe Game Reserve has only four chimpanzees!

Early this year, 2002, a three year old child was reportedly killed by a chimpanzee at the famous Gombe National Park where renowned Dr. J ane Goodall has worked for the past 42 years.

There is much concern in Kigoma and among some visiting tourists about these apparently nasty encounters between chimps and humans. We need to improve public education on chimpanzee behavior and attitudes towards man. Chimpanzees can be the best of man's friends as it has amply been demonstrated by those who keep them as pets and by researchers at Gombe and Mahale. But when man begins to hunt and capture them for meat and illegal trade they obviously begin to behave differently to say the least.

On further enquiring from Mr. Massawe, the Director of the Mahale Wildlife Research Centre in Kigoma, I have learned that police is continuing their investigation into this unfortunate event in which the poor security guard, Ndugu Adriano Msafiri, lost his life. I have also ascertained that Kitwe is not actually an official protected area in accordance with the law; but rather it is an area of scrub, a piece of land covered by plant community dominated by shrubs and small trees, a thicket covering several hundred hectares. This piece of land was allocated to the J ane Goodall Institute eight years ago to enable Dr. J ane Goodall and her colleagues to use as a sanctuary for orphaned chimpanzees and chimpanzees that had been rescued from poachers or from 'foreigners' involving themselves in trafficking chimpanzees illegally.

Although the area was fenced, it has not been a suitable refuge for the chimpanzees. The five or so young chimpanzees brought to the sanctuary in 1993 and 1994 were not sufficiently restrained and were inadequately provisioned. Some local Government officials were not entirely happy with the way in which the chimpanzees were being let loose and given so much freedom in an area so close to Kigoma Township. The area should have been designed more like a zoo; not simply fenced in! As the chimpanzees grew older they appear to have become bolder, more daring and more adventurous. This is the second incidence of a chimpanzee attacking a man and causing him grievous injury.

There is one intriguing puzzle: the fatal attack took place at night when the chimpanzees should have been asleep in their freshly prepared beds. Furthermore the deceased had his eyes gorged. All this has prompted the police in Kigoma to take keener interest in order to exdude any likely human criminality. We should not forget that the chimpanzee may be innocent after all. 